\title{
DIFFERENTIAL CYCLIC EMPLOYMENT RESPONSE IN A SUBREGION
}

\author{
Charles A. Campbell*
}

\begin{abstract}
Differences in employment responses in a substate area of Mississippi were examined between two recessionary periods using a shift-share procedure. The method allows separation of effects based upon both the nature of the particular recession and the nature of structural change between recessions. The method permits identification of effects that may be influenced by local or state policy makers. The need for additional analysis is shown using a dynamic shift-share procedure which indicates that the first method should not be used in isolation.

Regional changes in employment patterns occur in response to both secular and cyclic influences. Because changes in employment include both of these components, the examination of employment changes during only one period is likely to be misleading. An example of this phenomenon is shown in Barff and Knight (1988), where static and dynamic shift-share analyses are compared. Their results indicate that there may be wide differences between the two methods because changes in the industrial mix and growth fluctuations within the time periods are ignored in the static approach. Other researchers, Riefler (1986) and Mead and Ramsay (1982), suggest the same problem in a slightly different context. Concerned with the response of regional economies to cyclic activity, these authors sought to isolate the differential response between two recessions. The results indicate that intraregional structural change between two recessions may change the response of the region to a recession.

This is a particularly important question for policy makers in a region undergoing substantial change in industrial structure. At least since Fisher (1935) and Clark (1940) it has been suggested that the normal course of economic growth pushes an economy from specialization in agriculture and pastoral occupations (primary production) to an emphasis on manufacturing or industrial employment (secondary production) to the tertiary stage in which there is an emphasis on production of luxury goods and on trade and services. This scenario is depicted in the path-breaking works in national growth theory of Kuznets $(1971,1973)$. In fact, such structural changes appear to
\end{abstract}

\footnotetext{
*Assistant Professor of Economics, Mississippi State University
}

take place and are very noticeable in rural regions that recently have begun the transformation process. Given such secular change, successive recessions would not be expected to have the same effect on a region or sub-region. Such regions are dynamic, not static, thus it is expected that response to cyclical activity will change.

As the current U.S. economic recovery enters old age, the likelihood of a new recession grows ever greater and the likely response of a region to the potential new recession is becoming an important question for policy makers. If it were found that there are similarities in cyclic response in a region over a relatively short period and if policy could tailor such responses this would have important policy implications. Examining changes in responses during past recessions will not necessarily provide useful predictions of the future regional response, but it can provide a starting point. A procedure, first proposed by Mead and Ramsay (1982) and later used by Riefler (1986), exists for identifying those parts of the differentiated effects that have the potential to be influenced by policy makers.

The subregion used in this analysis is identified as Northeast Mississippi (NEM). The area is an economically congruous area and the 18 counties included in it were chosen after both statistical analysis and conferences with area businessmen. The area extends roughly from Oktibbeha and Lowndes counties on the south to the Tennessee border and from Lafayette county eastward to the Alabama border. The area is rural in nature, but manufacturing has grown rapidly and accounts for over 40 percent of nonagricultural employment. Most manufacturing employment in the area is in durable goods. There is substantial specialization within durable goods manufacturing with the Furniture and Fixtures sector dominating employment. In non-durable manufacturing, employment is highly concentrated in Apparel but the sector is declining. In nonmanufacturing sectors, employment is highly concentrated in government, trade, and services.

From 1970 through 1986, the national economy suffered through two major recessions that shared many similarities. These occurred approximately in 1975 and 1982. While the earlier recession technically began in 1974 , the NEM counties did not experience a decline in employment until 1975. Therefore, for the purpose of examining the effects of the recession on the area, 1975 
was chosen as the date of the earlier recession. Employment declined in the U.S. by 2.3 percent in 1975 , while employment in NEM declined by 5.7 percent. During 1982 U.S. employment declined by 1.5 percent while NEM employment declined by 4.8 percent. While the substantial portion of NEM employment in durable goods helps to explain the relatively strong effect of these recessions in the NEM region, it also explains why policy makers are concerned about future recessions.

\section{Method of Study}

Following the procedure of Mead and Ramsay (1982), this study started with a standard shift-share decomposition of employment. The components were defined as:

$$
\begin{gathered}
\text { ChE }=N S+I M+R S \\
N S=e_{i}^{t-1}\left(E_{i} / E_{t-1}-1\right)=e_{i}^{t-1} N \\
I M=e_{i}^{t-1}\left(E_{i}^{t} / E_{i}^{t-1}-E^{t} / E^{t-1}\right)=e_{i}^{t-1} I \\
R S=e_{i}^{t-1}\left(e_{i}^{t} / e_{i}^{t-1}-E_{i}^{t} / E_{i}^{t-1}\right)=e_{i}^{t-1} R
\end{gathered}
$$

Where:

$$
\begin{aligned}
\mathrm{ChE}= & \text { Change in employment in industry } \mathrm{i} ; \\
\mathrm{NS}= & \text { National Share (or National Growth Compo- } \\
& \text { nent); } \\
\mathrm{IM}= & \text { Industrial Mix; } \\
\mathrm{RS}= & \text { Regional Shift (or Competitive Position); } \\
\mathrm{e}_{\mathrm{i}}^{\mathrm{t}}= & \text { Regional Employment in Industry } \mathrm{i} \text { at time } \\
& \text { period } \mathrm{t} \\
\mathrm{E}_{\mathrm{i}}^{\mathrm{t}}= & \text { National Employment in Industry } \mathrm{i} \text { at time } \\
& \text { period t;and } \\
\mathrm{E}^{\mathrm{t}}= & \text { National employment at time period } \mathrm{t} .
\end{aligned}
$$

The decomposition of total employment is obtained by summing all components (NS, IM and RS) across all "i" industries. Incorporating equations (2) through (4) into equation (1) results in:

$$
\begin{aligned}
& C h E=e_{i}^{t-1}\left(E^{t} / E^{t-1}\right)+e_{i}^{t-1}\left(E_{i}^{t} / E_{i}^{t-1}-E^{t} / E^{t-1}\right) \\
& +e_{i}^{t-1}\left(e_{i}^{t} / e_{i}^{t-1}-E_{i}^{t} / E_{i}^{t-1}\right)=e_{i}^{t-1}(N+I+R)
\end{aligned}
$$

Here $\mathrm{N}$ is a vector of constants equal to the percentage change in overall national employment; $\mathrm{I}$ is a vector of differences in employment growth rates for each of the industries at the national level and the overall national growth rate; and $\mathrm{R}$ is a vector of differences between the employment growth rates for each of the industries at the regional and the national levels.
From equation (5) it is obvious that the decomposition shows that employment change depends upon four factors $\left(e_{i}^{t-1}, N I\right.$, and $\left.R\right)$. Letting $W$ denote $e_{i}^{t-1}$ and following the Mead and Ramsay (1982) extension of the decomposition by totally differentiating equation (5), the result is an estimate of the differential effect between two recessions:

$$
\mathrm{dChE}=\left[\mathrm{dW}\left(\mathrm{N}_{0}+\mathrm{I}_{0}+\mathrm{R}_{0}\right)\right]+\left[\mathrm{W}_{0}(\mathrm{dN}+\mathrm{dI}+\mathrm{dR})\right]
$$

where the subscript 0 denotes the base period.

The first part of equation (7), [dW( $\left.\mathrm{N}_{0}+\mathrm{I}_{0}+\mathrm{R}_{0}\right)$ ], is denoted the pure employment effect. The second part, $\left[\mathrm{W}_{0}(\mathrm{dN}+\mathrm{dI}+\mathrm{dR})\right]$, is denoted the pure recession effect.

The pure employment effect embodies all the characteristics of the first recession constant. Thus all changes here were due totally to changes in the employment base which occurred between the two recessions. Positive values for the pure employment effect indicate that the changes which occurred in the employment base tended to reduce the effects of the later recession. Negative values for the pure employment effect indicate that the changes in the employment base tended to exacerbate the effects of the later recession. The pure employment effect can be further decomposed into $\mathrm{dWN}_{0}, \mathrm{dWI}_{0}$, and $\mathrm{dWR}_{0}$. Here, $\mathrm{dWI}_{0}$ indicates the extent to which the changing industrial structure of the region was into industries which performed better $(+)$ or worse $(-)$ than the overall national industrial sector during the base period recession. The shift of employment into industries that maintained a positive competitive position is indicated by $\mathrm{dWR}_{0}$.

The pure recession effect is a measurement of the differences in the impacts of the two recessions that are attributable to specific characteristics of the recessions, with $\mathrm{W}_{0} \mathrm{dI}$ indicating the change in employment due to the changing industrial mix and $\mathrm{W}_{0} \mathrm{dR}$ indicating how employment would have changed due only to changes in regional competitiveness.

The formulation described above is similar to a Laspeyres index and thus is expected to overestimate the differential. Indexes which use the beginning year of a range as the base produce an index that represents a maximum estimate of the increase from the beginning to the ending year. A reformulation similar to a Paasche index could be constructed simply by choosing the latter recession as the base. A Paasche index estimates the same changes using the last year as the base, producing a minimum estimate of the change. Riefler (1986) suggested averaging the results of the two methods to ameliorate the over/under-estimation problem. This is the procedure that was taken in this study. 


\section{Empirical Results}

The data employed in the analysis were aggregated from BEA (Bureau of Economic Analysis) county data for the 18 county area and include all manufacturing employment by 2 digit SIC codes and non-manufacturing, nonagricultural employment by 1 digit SIC codes. Equations (1) through (4) were applied to the data to produce the shift share components for the data, aggregated across industries (Table 1). Non-agricultural employment losses in the NEM area were very close in the two recessions, with employment loss in the earlier recession exceeding that of the later recession by 625 jobs. The loss of 717 fewer jobs due to change in the industrial mix in the second recession was partially countered by a relative decline in the competitive position of the region that caused a loss of 303 more jobs in the second recession.

In the latter recession the NEM region lost 9,109 jobs, compared to 9,734 during the earlier recession, for a difference of 625 jobs between the two recessions. The reformulated Mead/Ramsay model estimated a differential of the same magnitude (Table 2).

Between 1974 and 1981 the employment base expanded by 12.2 per cent from an initial level of 170,106 . Between the two recessions there was a gross change of employment of 27,000 jobs. Of these, 24,158 were gained in 18 industries while the remaining 11 sectors lost 2,842 jobs.

The pure employment effect and all of its components were negative, indicating that the change in the regional employment base between 1974 and 1981 exacerbated the effects of the latter recession.

If the 1981-82 and 1974-75 national recessions had been of the same magnitude, the expected loss of jobs in 1982 would have been 348 jobs. The restructuring of the regional employment base during the intervening years reduced the loss to 202 jobs. Finally, the pure employment effect showed an increased loss of 1,069 jobs in the latter recession because industries in NEM performed worse than their national counterparts.
The pure recession effect is the difference in employment due to differences in the recessions. Given the nature of the 1982 recession, the NEM area would have expected the employment decline to be 558 less in 1982 than in the earlier recession. Both the industry and regional effect components indicated lower job loss in the latter recession. The changing industry mix saved 919 jobs and changes in the competitiveness of firms in the NEM area resulted in 768 fewer lost jobs. Thus the total improvement explained by the nature of the recession and its associated sub-components was 2,244 more than the increased losses due to the pure employment effect.

Mead and Ramsay (1982) characterized the components of the pure employment and pure recession effect as exogenous or endogenous factors. The term endogenous refers to those factors that can be influenced by state policy makers through financial and tax incentive programs. For example, state policy makers can provide low interest loans and financial incentives to modernize plants, to improve infrastructure, including general education, and to retrain the labor force. Such programs can alter the employment base and therefore all components of the pure employment effect are categorized as endogenous factors.

The pure recession effect contains both exogenous and endogenous elements. The most obvious exogenous factor is the national growth component of the recessionary effect (dN). Obviously, state policy makers have no tools to alter overall national growth. The industrial mix changes (dI) are similar, being the difference between the national growth rate for the particular industry and that for the nation overall. An exception to this generalization occurs (as pointed out by Riefler, 1986) when the region constitutes a major portion of the national industry.

On the other hand, changes in regional competitiveness (dR) certainly can be influenced through a variety of tactics. Remembering that $R$ is the difference between growth rates at the regional and at the national levels for a given industry, improvements can be fostered through tax incentives, guaranteed loans for plant expansion and modernization, improvements in labor force quality and

Table 1

Shift-Share Analysis of Employment Changes in Northeast Mississippi: Total Effect for 1974-75 and 1981-82

\begin{tabular}{lcc}
\hline \hline & $1974-75$ & $1981-82$ \\
\hline National Growth Effect & $-3,126$ & Jobs \\
Industry Mix Effect & $-3,093$ & $-2,917$ \\
Regional Share (Competitive Effect) & $-3,515$ & $-2,376$ \\
Total Change & $-3,816$ \\
\hline
\end{tabular}


Table 2

Decomposition of the Differential Effect of the 1974-75 and 1981-81 Recessions on Employment in Northeast Mississippi, by Number and Percent

\begin{tabular}{|c|c|c|c|}
\hline Item & \multicolumn{3}{|c|}{ Jobs } \\
\hline \multirow{2}{*}{ Pure Employment Effect } & Number & \multicolumn{2}{|c|}{ Percent } \\
\hline & & Endogenous & Exogenous \\
\hline $\mathrm{dWN}$ & -348 & -55.7 & \\
\hline dWI & -202 & -32.3 & \\
\hline $\mathrm{dWR}_{0}$ & $-1,069$ & -171.0 & \\
\hline Total & $-1,619$ & & \\
\hline \multicolumn{4}{|l|}{ Pure Recession Effect } \\
\hline $\mathrm{W}_{0} \mathrm{dN}$ & 558 & & +89.3 \\
\hline $\mathrm{W}_{0}^{0} \mathrm{dI}$ & 918 & & +146.9 \\
\hline $\mathrm{W}_{0} \mathrm{dR}$ & 768 & +123.9 & \\
\hline Total & 2,244 & & \\
\hline Grand Total & 625 & & \\
\hline
\end{tabular}

(through job specific or industry specific training) improvements in general infrastructure.

In general, all components are at least somewhat endogenous except changes in national growth and (in most cases) changes in the industrial mix. Noting these categorizations, the implications of Table 2 are that unlike Mead and Ramsay (1982), but similar to the results found by Riefler (1986): There is a significant potential for policy makers to influence the sensitivity of the NEM area to cyclic downturns. It also should be noted that since $\left(\mathrm{I}_{1}-\mathrm{I}_{0}\right)$ and $\left(R_{1}-R_{0}\right)$ are non-zero, the economy has been somewhat unstable in the sense that the effects in the two recessions were different, and that an industry can be a good performer in one recession but a poor one in the next.

Once the differential effects of two recessions have been decomposed, the decomposition can be analyzed to suggest industries that could be influenced by policy makers to reduce the deleterious effects of subsequent downturns. It should, however, be remembered that the goals of reducing the effects of subsequent recessions and of maximizing employment growth in the long run may conflict. A useful addition to the analysis that can help to identify such conflicts is the dynamic evaluation of shiftshare suggested by Barff and Knight (1988). Such analysis should examine a longer period, including both recessions and growth sub-periods. The results of both the differential analysis and the dynamic shift-share analysis then can be used in conjunction with a set of goals established by policy makers.

Keeping in mind that the endogenous factors from the decomposition are the employment effects and the regional performance vector $\left(W d R_{0}\right)$ of the recession effects, an examination of those factors by industry (Table 3 ) should suggest policies to support or improve industries that contributed to reducing the effect of 1981-82 recession. Positive pure employment effects indicate that the change in employment base between the onset of the two recessions would lessen the employment impact of the subsequent recession. Using this rationale, policy makers might want to encourage employment redistribution into such sectors. These would include Transportation Equipment, Apparel and Textile products, and Rubber and Miscellaneous products. The redistribution would be away from industries that exhibited negative pure employment effects such as Construction, Furniture and Fixtures, and Wholesale and Retail Trade.

A positive value for regional response vector $W_{d R_{0}}$ indicates sectors that improved competitive performance in the latter recession (relative to the earlier recession). The industries most responsible for job savings through this improvement, and which would merit the attention of policy-makers, were Mining, Paper, Electrical Equipment, Transportation Equipment, Wholesale and Retail Trade, and Services.

Consideration of the results of a dynamic ShiftShare analysis might alter the policy conclusions drawn from the decomposition. A good example is the furniture industry in the NEM area. Overall, the pure employment effect was negative for this sector, indicating that the increase in its employment base contributed to worsening the second recession. The only element of the pure employment effect that was positive was a small effect in the 


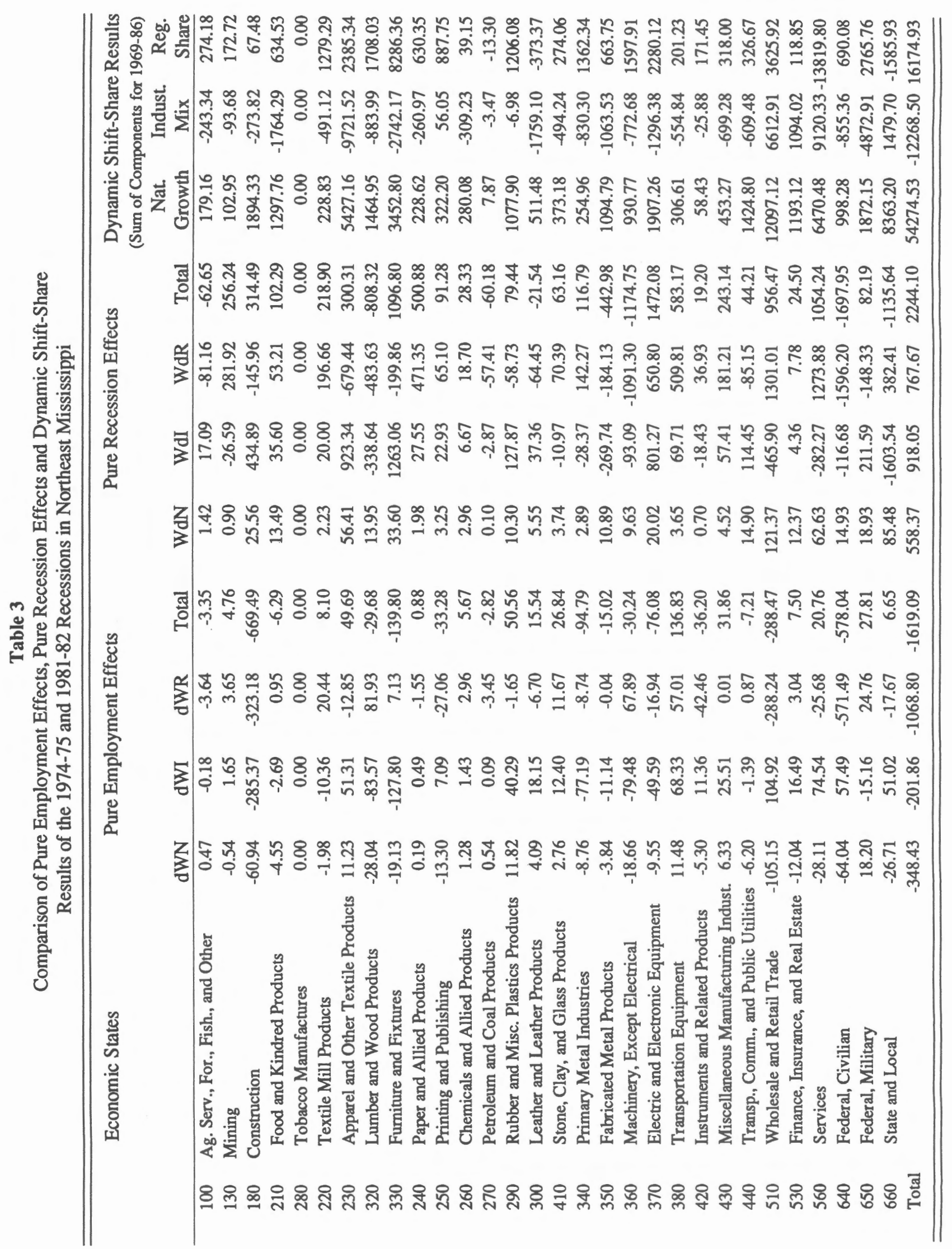


regional share vector $\left(d W R_{0}\right)$. The other endogenous element $\left(\mathrm{W}_{0} \mathrm{dR}\right)$, the change in the regional share vector of the pure recession effect, also was negative. It would seem that policy makers concerned with limiting employment declines during recessions would want to steer the local area economy away from the furniture sector. The results of the dynamic shift-share analysis aggregated across all years from 1969 to 1986 indicated that the industrial mix component for furniture was negative, simply meaning that furniture is, nationally, a slow growth sector. The industrial mix effect was overwhelmed, however, by a positive national growth component and an extremely strong competitive effect (or regional share). Employment growth in the sector (230 percent during 1969 to 1986) amounted to a compound annual growth rate of 5 percent. During the 1969 to 1986 period furniture employment was one of the strongest growth industries in the region, increasing its competitive advantage steadily through the period and growing from 4.8 percent of total area employment in 1969 to nearly 8 percent in 1986. It is true that, as with most durable goods manufacturing sectors, this sector is hit hard during recessions, but the question is whether policy makers will be willing to trade a strong source of employment growth for less growth but more stability.

While the furniture industry is a more extreme example than many other sectors it demonstrates the potential for policy conflicts and the need for clear regional goals.

\section{Summary}

The use of a decomposition analysis such as that of Riefler (1986) and Mead and Ramsay (1982) can be an important tool for examining cyclical fluctuations and may be a starting point from which policy makers can launch countercyclical policies. There are significant problems however. First, the performance of individual economic sectors between two recessions may not be a good indicator of what will happen in subsequent recessions. Second, before policy recommendations are made, other factors also must be considered. The dynamic shift-share analytical technique helps to fill the gap.

\section{References}

Barff, Richard A. and Knight, Prentice L. III. "Dynamic ShiftShare Analysis." Growth and Change. 19 (2) (1988). 1-10. Clark, Colin. The Conditions of Economic Progress. London: Macmillan, 1940.

Fisher, Allen G. B. The Clash of Progress and Security. New York: Augustus M. Kelley (First Published in 1935), 1966.

Kuznets, Simon. Economic Growth of Nations: Total Output and Production Structure. Cambridge, Mass.: Belknap Press, 1971.

Kuznets, Simon. Modern Economic Growth: Rate, Structure, and Spread. New Haven: Yale University Press, 1973.

Mead, Arthur C. and Ramsay, Glenworth A. "Analyzing Differential Responses of a Region to Business Cycles." Growth and Change. 13 (3) (1982). 38-42.

Riefler, Roger F. "Comparative Cyclic Behavior of an Agricultural Economy." The Review of Regional Studies. 16 (1) (1986). 24-30. 